The concentrated liquid is certainly quite fluid: liquid readily flows out of the cut ends of glands of spinning silkworms (Magoshi, J., Magoshi, Y. \& Nakamura, S. Rep. Progr. Polymer Phys., Japan 23, 747; 1980). The precipitation step that occurs during spinning seems to depend on a critical shear rate being reached. In vitro measurements on solutions of less than five per cent show that precipitation occurs if liquid silk is sheared at rates greater than $50 \mathrm{~s}^{-1}$. The silkworm spins the fibre at about $1 \mathrm{~cm} \mathrm{~s}^{-1}$ from the anterior gland, which narrows to $50 \mu \mathrm{m}$ at the entrance. This corresponds to a shear rate of about $1 \mathrm{~s}^{-1}$ and causes precipitation of silk at the much higher concentrations found in vivo (Kataoka, K., \& Uematsu, I. Kobunshi Ronbunshu Engl. Ed. 6, 621; 1977). Magoshi et al. also report that the change to the $\beta$-sheet structures occurs at draw ratios of about four and that the silk can be induced to flow out of cut glands in a liquid crystal form.

From recent efforts to prepare highstrength synthetic fibres, it has become clear that to produce high levels of orientation the inter-chain forces must be controlled so as to permit slippage of the chains past one another while preventing rapid relaxation back to a randomly coiled state. Strong aromatic polyamide fibres such as Kelvar, are produced by spinning from liquid crystalline solutions in which the chains are locally aligned even before starting, thereby greatly increasing the orientation. Apparently silk production is similar, in that the aggregated state promotes local alignment of the chains while still keeping them in solution. They then easily spin to high orientations and to moduli that are comparable with the highest values achievable with nylons and about half those of Kelvar. The change from coiled to rigid conformation that happens with increasing silk concentration apparently corresponds to the 'induced rigidity', believed to occur in stiff polymers in solution (Matheson, R.R. Mol. Cryst. Liq. Cryst. 105, 315; 1984). Again we have failed to recognize a natural process until rediscovering it the hard way.

Paul Calvert is in the School of Chemistry and Molecular Sciences, University of Sussex, Falmer, Brighton BNI $9 Q J$, UK.

\title{
Icythyology
}

\section{The biology of coelacanths}

\section{from Jared M. Diamond}

ON 22 December 1938, a taxi driver on the docks of East London, South Africa, was hailed by a lady with a very oily dead fish that proved to be the coelacanth Latimeria chalumnae, sole survivor of a group of fish that had been believed extinct for 70 million years and traditionally considered close to the ancestor of all land vertebrates. Since then, many other specimens have been captured and pickled or frozen but scientists have yet to observe a healthy live specimen. But much has been learned from preserved specimens about ecology, sensory biology, reproductive biology, physiology, and taxonomic affinities of this 'living fossil'1-3.

As for Latimeria's geographical distribution and habitat, all but the first specimen were caught by native fishermen off two of the Comoro islands, between Madagascar and the east coast of Africa. Most specimens have been taken at depths of 100-300 metres as an accidental byproduct of night fishing for oilfish, and the apparent restriction of Latimeria to these two islands is probably an artefact of how socio-economic and oceanographic conditions constrain the search for oilfish. The South African specimen taken 2,000 miles from the Comoros is the only proof of a wider distribution, but coelacanths may eventually turn up at other seamounts and banks in the western Indian Ocean.

Most likely, coelacanths perch on a reef, lunge for prey and suck it in, rather like a grouper ${ }^{2}$. They feed on fish and cuttlefish, swallowed whole, that live on or near the bottom of reefs in deep water. Latimeria's most distinctive anatomical feature relevant to feeding is a joint across the skull that permits rotation by up to 15 degrees and thereby widens the gape and increases the strength of the bite ${ }^{4}$. Such intracranial joints are known from some fossil fish but no other living fish. Sensory equipment for prey detection includes large, nearly colour-blind eyes that are adapted to low light levels, densely packed rods but very few cones, and a large cavity in the snout, the rostral organ, which has the structure of an electroreceptor ${ }^{5}$.

One of the most surprising discoveries about Latimeria concerns its reproductive biology. Initially, the coelacanth was assumed to lay eggs for external fertilization, like most fish, because males lack a penis, pelvic claspers, modified anal fins or any other obvious copulatory organ. Then, dissection of a female revealed shell-less and very large eggs, $8.5-9 \mathrm{~cm}$ in diameter ${ }^{6}$. Finally, Smith et al. proved that the eggs are fertilized and hatch internally by finding five miniature coelacanths, $30-33 \mathrm{~cm}$ long, in the oviduct of another female ${ }^{7}$. Dates of capture suggest that the gestation period is around 13 months. How the male achieves internal fertilization remains a mystery; two pairs of erectile caruncles flanking the cloaca may play a part ${ }^{8,9}$.

The other big surprise concerns the osmoregulation of Latimeria. Living marine animals osmoregulate in one of three ways: by being iso-osmotic and (1)1985 Nature Publishing Group similar in ion concentrations to sea water (hagfish and marine invertebrates); by being iso-osmotic, despite having ion concentrations far below those in sea water, through retaining urea and trimethylamine oxide (sharks); or by having ion concentrations far below those in sea water and being hypotonic but drinking sea water and excreting salt to remain in water balance (modern bony fish). Latimeria proves to resemble sharks rather than modern bony fish $^{10,11}$. With $197 \mathrm{mM} \mathrm{Na}^{+}$and $187 \mathrm{mM}$ $\mathrm{Cl}^{-}$in its blood, as in bony fish, and $377 \mathrm{mM}$ urea and $122 \mathrm{mM}$ trimethylamine oxide, both the blood and urine of the coelacanth are iso-osmotic to sea water.

The osmoregulatory resemblance of Latimeria to sharks begs the question of its taxonomic affinities. Traditionally, coelacanths have been considered the sister group of the rhipidistians, an extinct group of bony fish that gave rise to amphibians and thence to other land vertebrates. Lagios, however, considers coelacanths the sister group of chondrichthyans (sharks and rays) on the basis of similarities not only in urea retention but atso in pituitary structure, pancreatic structure and the presence of a salt-secreting rectal gland ${ }^{2,12}$. Other authors argue that these similarities do not necessarily ally coelacanths with sharks ${ }^{2,10,13}$. For example, urea retention arose independently in lungfish, certain frogs and some primitive ray-finned fish and so may also have arisen independently in coelacanths and sharks.

Thus, the dogma on which the current generation of biologists was reared - that coelacanths are close to the ancestors of tetrapods - is under vigorous debate. But the outcome is unlikely to shake their image as a symbol of long preservation without change. Thus, Time Magazine once branded Richard Nixon as a "coelacanth of American anti-communism", and a British MP ridiculed a fellow MP as a 'coelacanth' on the grounds that from his long silence in that august assembly it was a surprise to find him still alive ${ }^{2}$. Whether these calumnies of coelacanths are taxonomically justified is a question that can be resolved only when political conditions allow fresh specimens to be obtained from the Comoro islands or neighbouring waters.

1. Thomson, K.S. Nat. Hist. 82, No. 2, 58 (1973).

2. McCosker, J.E. \& Lagios, M.D. The Biology and Physiology of the Living Coelacanth (Occas. Pap. Calif. Acad. Sci. No. 134, 1979).

3. Schopf, T.J.M. A. Rev. Earth planet. Sci. 12, 245 (1984). 4. Thomson, K.S. Science 153, 999 (1966).

5. Bemis, W.E. \& Hetherington, T.E. Copeia 467 (1982).

6. Anthony, J. \& Millot, J. C.R. Acad. Sci., Paris 274, 1925 (1972).

Smith, C.L. et al. Science 190, 1105 (1975).

8. Millot, J. \& Anthony, J. Bull Mus. nat. Hist. Nat. Ser. 2 32, 287 (1960).

9. Griffith, R.W. \& Thomson, K.S. Nature 242, 617 (1973) 10. Griffiths, R.W. \& Pang, P.K.T. Occas. Pap. Calif. Acad. Sci. No. 134, 79 (1979).

11. Griffith, R.W. Proc. R. Soc. B280, 329 (1980).

12. Lagios, M.D. Copeia 942 (1982).

13. Lauder, G.V. Copeia 942 (1980).

Jared M. Diamond is at the University of California Medical School, Los Angeles, California 90024, USA. 